\title{
Follicular ovarian cysts in stillbirths and neonates
}

\author{
D. J. DESA \\ From the Department of Pathology, McMaster University, Hamilton, Ontario, Canada
}

\begin{abstract}
deSa, D. J. (1975). Archives of Disease in Childhood, 50, 45. Follicular ovarian cysts in stillbirths and neonates. A review of the histology of 332 ovaries from stillbirths and neonatal deaths within the first 28 days of life showed that follicular cysts, lined by granulosa epithelium and having a diameter greater than $1 \mathrm{~mm}$ on a microscopical section, were present in 113 infants. In 48 cases multiple cysts were present, while in 65 only a single cyst satisfying the criteria was found. There was an excess number of infants of low birthweight score among those with multiple cysts and the results were highly significant. Cysts, whether single or multiple in distribution, were commoner with increasing gestation, and possibly occurred more commonly in the infants of diabetic mothers and in infants where pregnancy had been complicated by rhesus isoimmunization.

The nature of the changes seen in the granulosa lining and theca internal layer surrounding the cysts suggested that these cysts were not some degenerative phenomenon but occurred in response to stimulation. It is suggested that homologous changes may occur in the testis of the dysmature male. The possible significance of these findings with regard to hormonal imbalance in the growth-retarded infant is considered, and the need for closer attention to endocrine function in these infants stressed.
\end{abstract}

It is well known that cystic follicles are frequent findings in the ovaries of neonatal infants (ValdesDapena, 1967) but little attention is paid to them in descriptions of the ovary of the newborn. This study was originally planned to obtain some idea of the frequency of ovarian follicular cysts, and though it did not achieve this objective, certain other features of interest emerged.

\section{Materials and methods}

The necropsy records of the Department of Pathology, Radcliffe Infirmary, Oxford, from 1948 to 1972 , were searched for all female stillbirths and neonatal deaths at 28 days of age or less. Necropsy histology was then reviewed and only those cases where slides of ovarian tissue were available were retained for the purpose of this study. During this 25-year period there were 987 necropsies on female infants, but ovarian tissue was available in 332 cases only.

Information on the infants' birthweight and gestation, complications of pregnancy and postnatal life, and major necropsy findings were recorded from the necropsy report or, if necessary, from tracing the clinical record. In most cases the quality of the sections obviated the

Received 29 May 1974. need for further sections, but where indicated fresh sections were cut.

For the purposes of this study, follicular cysts were defined as cystic structures lined by recognizable granulosa epithelium and with the greatest diameter in excess of $1 \mathrm{~mm}$ on a microscopical section. Such a definition did not take into account the presence or absence of the oocyte and differs from that used by Pryse-Davies and Dewhurst (1971), whare the critical dimension was $0.5 \mathrm{~mm}$ on a section, but agrees with Spivack (1934). The reasons for this distinction will become apparent when considering the results.

\section{Results}

Developmental changes. All stages of evolution of the follicle were identified from very early primordial follicles to established Graafian (secondary) follicles with the eccentrically situated ovum surrounded by its cumulus ovaricus, the liquor folliculi filling the antrum, the lining granulosa layer, and theca interna (Fig. 1). As noted by other authors the theca externa was not a well established layer. As in Fig. 1, an established Graafian follicle can often attain a diameter of 0.3 $\mathrm{mm}$ on a microscopical section, and it was felt that 


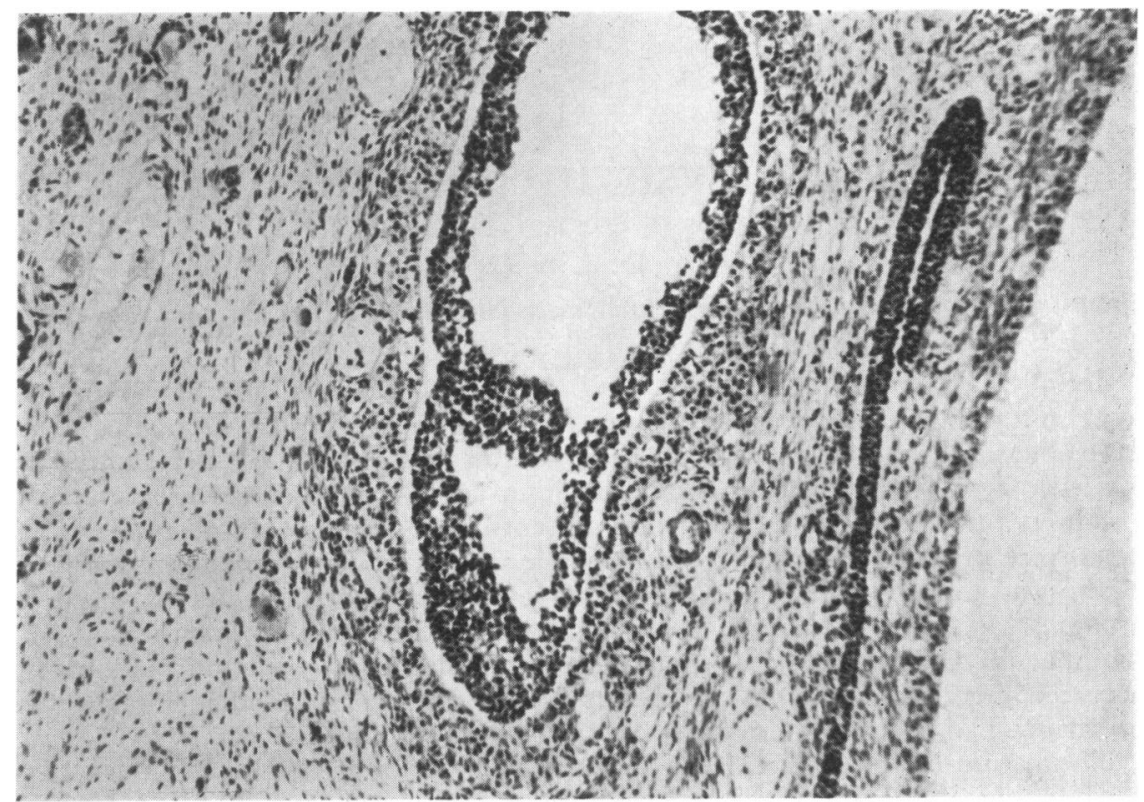

FIG. 1.-A fully developed Graafian (secondary) follicle is shown; note the considerable size of the antrum. (H. and E. $\times 166$.)

selection of $0.5 \mathrm{~mm}$ as the critical diameter defining cysts (cf. Pryse-Davies and Dewhurst, 1971) gave too narrow a margin for normal variation. Established Graafian follicles were seen in every slide of ovarian material in infants over 37 weeks' gestation, and in the mature female infant they represent a normal phenomenon at birth.
Follicular cysts. Ovaries with cystic lesions could be readily subdivided into those with single cysts or those with multiple cysts. While most cases with 'multiple cysts' had only 3 or 4 such structures, there were several cases where the entire ovarian architecture was distorted. Fig. 2 illustrates such an example, an appearance very

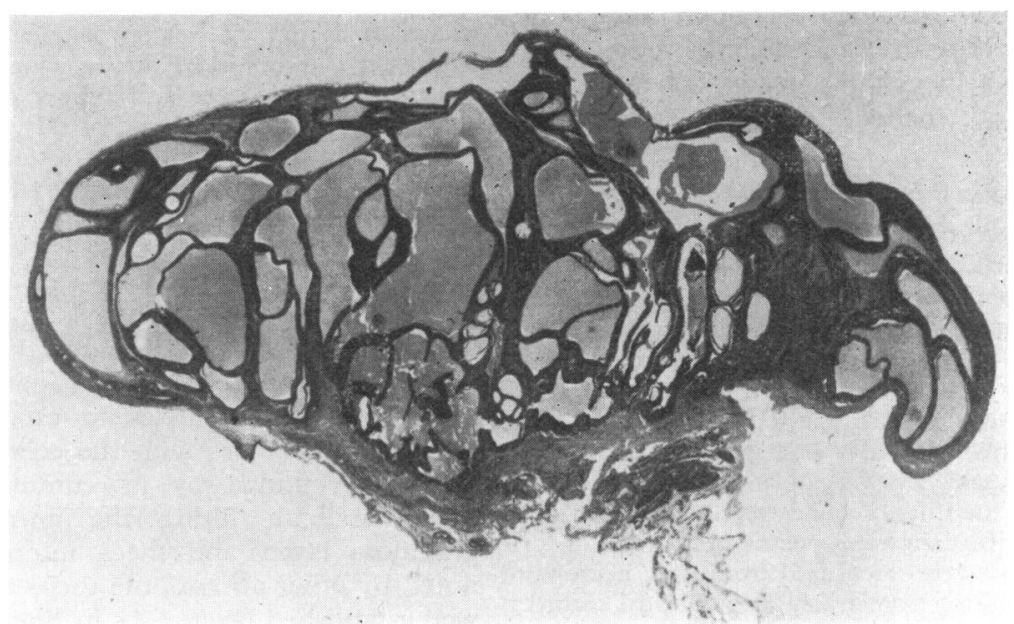

FIG. 2.-Low-power view of an ovary with a considerable number of follicular cysts causing considerable distortion of the architecture. (H. and $E . \quad \times 10$.) 
similar to that depicted by Ober and Bernstein (1955).

Histological features. The granulosa epithelium lining the cysts was, in most cases, moderately attenuated, but in all instances was readily recognizable as a layer distinct from the underlying theca interna. When two cysts impinged on each other the degree of tissue attenuation, particularly of the granulosa layer, was most pronounced. However, as seen in Fig. 3, even in these less favourable

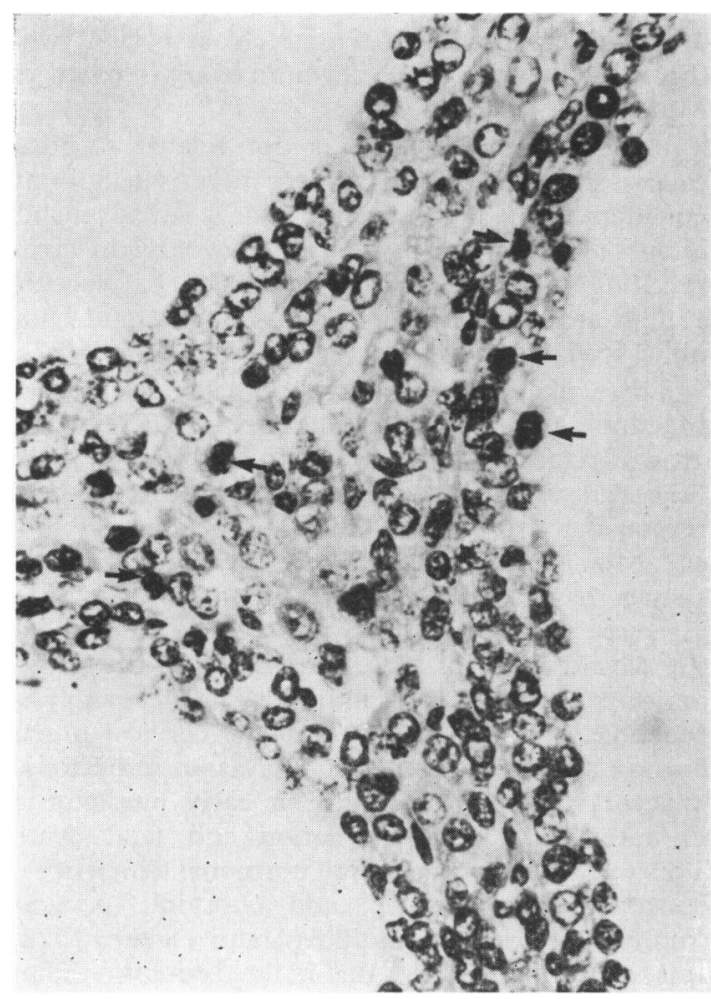

Fig. 3.-Junctional area of 3 follicular cysts showing numerous mitotic figures (arrowed) within the granulosa and thecal cell layers. Note also the abundant foamy cytoflasm of the thecal cells. (H. and $E . \quad \times 488$.)

circumstances there was evidence of considerable activity. Mitotic figures in both the granulosa and thecal layer were fairly frequent and several of the thecal cells had abundant foamy cytoplasm suggesting an early stage of luteinization. In the majority of instances no oocyte could be identified within the cyst lining, though occasionally the presence of an apparently viable oocyte could be seen. The fluid of the cyst was usually intensely eosinophilic but attempts at characterizing the component elements of the fluid by histochemical methods were very irregular and unreliable.

Birthweight and gestation. These findings are shown in Tables I and II. Birthweight score

TABLE I

Ovarian follicular cysts and birthweight score

\begin{tabular}{c|c|c|c|c}
\hline \multirow{2}{*}{$\begin{array}{c}\text { Birthweight } \\
\text { score }\end{array}$} & \multicolumn{3}{|c|}{ Infants with } & \\
\cline { 2 - 3 } & No cysts & $\begin{array}{c}\text { Single } \\
\text { cysts }\end{array}$ & $\begin{array}{c}\text { Multiple } \\
\text { cysts }\end{array}$ & Total \\
\hline-2 & $17(8)$ & $7(11)$ & $18(38)$ & 42 \\
-1 & $28(13)$ & $12(19)$ & $11(23)$ & 51 \\
0 & $152(69)$ & $45(69)$ & $17(35)$ & 214 \\
$+1,+2$ & $22(10)$ & $1(1)$ & $2(4)$ & 25 \\
\hline Total & $219(100)$ & $65(100)$ & $48(100)$ & 332 \\
\hline
\end{tabular}

Note: Figures in parentheses indicate percentages within each of the three groups of infants.

TABLE II

Association between presence or absence of cysts and gestational age

\begin{tabular}{c|c|c|c}
\hline $\begin{array}{c}\text { Gestational } \\
\text { age (wk) }\end{array}$ & $\begin{array}{c}\text { Infants without } \\
\text { cysts }\end{array}$ & $\begin{array}{c}\text { Infants with } \\
\text { cysts }\end{array}$ & Total \\
\hline 33 & $130(93)$ & $10(7)$ & $140(100)$ \\
$34-37$ & $62(63)$ & $36(36)$ & $98(100)$ \\
38 & $27(29)$ & $67(71)$ & $94(100)$ \\
\hline Total & 219 & 113 & 332 \\
\hline
\end{tabular}

Note: Figures in parentheses indicate the percentage of infants with or without cysts in the three groups by gestational age.

was assessed as described by Gruenwald (1969). Thus, infants whose birthweight fell within a range of $1 \mathrm{SD}$ around the mean for their gestation (Butler and Alberman, 1969) were given a birthweight score of 0 ; those with a birthweight of between 1 and 2 SD below the mean for gestation were scored -1 ; while those with a range between 1 and 2 SD above the mean for gestation were given a score of +1 . A score of -2 or +2 implies similarly birthweight less than 2 SD below the mean, or greater than $2 \mathrm{SD}$ above the mean, respectively.

The results show clearly the excess of infants of low birthweight score $(-1$ and -2$)$ among the cases with multiple cysts, and the differences are highly significant $\left(x^{2}=43.56, P<0.001\right)$ when infants with multiple cysts are compared to those with no cysts. Infants with single cysts occupy an intermediate position. 
When analysed according to gestational age (Table II) it is clear that cysts whether single or multiple, are commoner with increasing gestation, but no clear differences were seen between infants with single or multiple cysts, and they are grouped together in the table.

Other associated features. These are shown in Table III and are difficult to interpret due to the

TABLE III

Follicular cysts and associated features

\begin{tabular}{|c|c|c|c|c|}
\hline \multirow{2}{*}{ Clinical features } & \multicolumn{3}{|c|}{ Infants with } & \multirow[b]{2}{*}{ Total } \\
\hline & $\begin{array}{l}\text { No } \\
\text { cysts }\end{array}$ & $\begin{array}{c}\text { Single } \\
\text { cysts }\end{array}$ & $\begin{array}{l}\text { Multiple } \\
\text { cysts }\end{array}$ & \\
\hline $\begin{array}{l}\text { Hypertension/toxaemia }{ }^{\star} \\
\text { Antepartum haemorrhage } \\
\text { Intrapartum anoxia } \\
\text { Rhesus isoimmunization } \\
\text { Maternal diabetest } \\
\text { Cord prolapse } \\
\text { Others } \\
\text { (a) Congenital } \\
\text { malformation } \\
\text { 'b) Other maternal¥ } \\
\text { disease }\end{array}$ & $\begin{array}{r}27 \\
26 \\
19 \\
17 \\
8 \\
11\end{array}$ & $\begin{array}{r}9 \\
10 \\
6 \\
6 \\
1\end{array}$ & $\begin{array}{r}3 \\
7 \\
6 \\
9 \\
10 \\
-\end{array}$ & $\begin{array}{l}39 \\
43 \\
32 \\
32 \\
24 \\
12\end{array}$ \\
\hline Total & 219 & 65 & 48 & 332 \\
\hline
\end{tabular}

$\star 8$ with complicating antepartum haemorrhage.

t4 with complicating hypertension, 1 patient in this group with added antepartum haemorrhage.

$\$ 5$ with urinary tract infection, 2 with kyphoscoliosis, 1 with epilepsy.

initial bias in selecting cases where the ovary was sampled. It appears, however, that a high proportion of the female infants of diabetic mothers and those where the pregnancy was complicated by rhesus isoimmunization have multiple follicular ovarian cysts, and this agrees with the findings of Ahlvin and Bauer (1957) and Pryse-Davies and Dewhurst (1971).

\section{Discussion}

Follicular cysts in the adult ovary are traditionally regarded as being derived from aberrant development of the Graafian follicle and there is no evidence to challenge such a view in either the adult or the fetal state. The structure of their lining, however, indicates that the follicular cysts of the newborn ovary are not due to a passive degenerative phenomenon, and in fact Morison (1970) ascribes their development to excessive stimulation by gonadotrophin. During pregnancy the most likely source of gonadotrophin is from the placenta and the presence of multiple cysts would indicate either raised level of secretion or an exaggerated sensitivity to circulating chorionic gonadotrophin.

In some of the situations where a greater frequency of multiple cysts may be expected, like maternal diabetes and rhesus isoimmunization (Ahlvin and Bauer, 1957; Pryse-Davies and Dewhurst, 1971), placental enlargement is known to occur and this might be sufficient to explain the raised levels of chorionic gonadotrophin (Loraine and Mathew, 1953; McCarthy and Pennington, 1964; Connon, 1964). High levels of chorionic gonadotrophin have been described in pre-eclamptic toxaemia (Loraine and Mathew, 1950) and toxaemia of pregnancy has been tentatively associated with theca luteinization of the newborn ovary (Govan and Mukherjee, 1950).

In small-for-dates infants not related to these causes, alternate explanations for increased chorionic gonadotrophin effect are necessary, since in such infants placental size parallels the lower birthweight, resulting in a near normal regression of placental surface area against body weight (Aherne and Dunnill, 1966).

There is evidence that anomalous endocrine function may exist in dysmature, small-for-dates, growth-retarded infants. Cathro, Forsyth, and Cameron, (1969) showed that steroid excretion in response to stress was likely to be depressed in small-for-dates infants. Blum et al. (1969) have shown that in small-for-dates infants, depletion of glycogen stores cannot be the sole explanation for the development of hypoglycaemia and their work indicates a subtle failure of glycogenolysis. Macdonald (1972) used persistent cervical mucus ferning after 16 weeks' gestation as an indicator of 'placental insufficiency' and an early predictor of intrauterine growth retardation and fetal death. This was related to an overall hormonal deficiency of oestrogen, progesterone, and chorionic gonadotrophin (Macdonald, Goulden, and Oakey, 1972). It is tempting to suggest that in the dysmature infant after an initial decrease in chorionic gonadotrophin during early pregnancy, a compensatory increase occurs later in pregnancy. This, however, is blind speculation and merely underlines the need for accurate assessment of the hormonal status in such babies. The role of the theca interna in any such assessment is likely to be of considerable importance. Histochemical studies show considerable activity of several of the enzymes necessary for steroid production, and there is a distinct increase in activity of these enzymes in the theca interna of cystic follicles (Richardson, 1967; Pryse-Davies and Dewhurst, 1971).

It is probable that in the fetal testis a lesion 


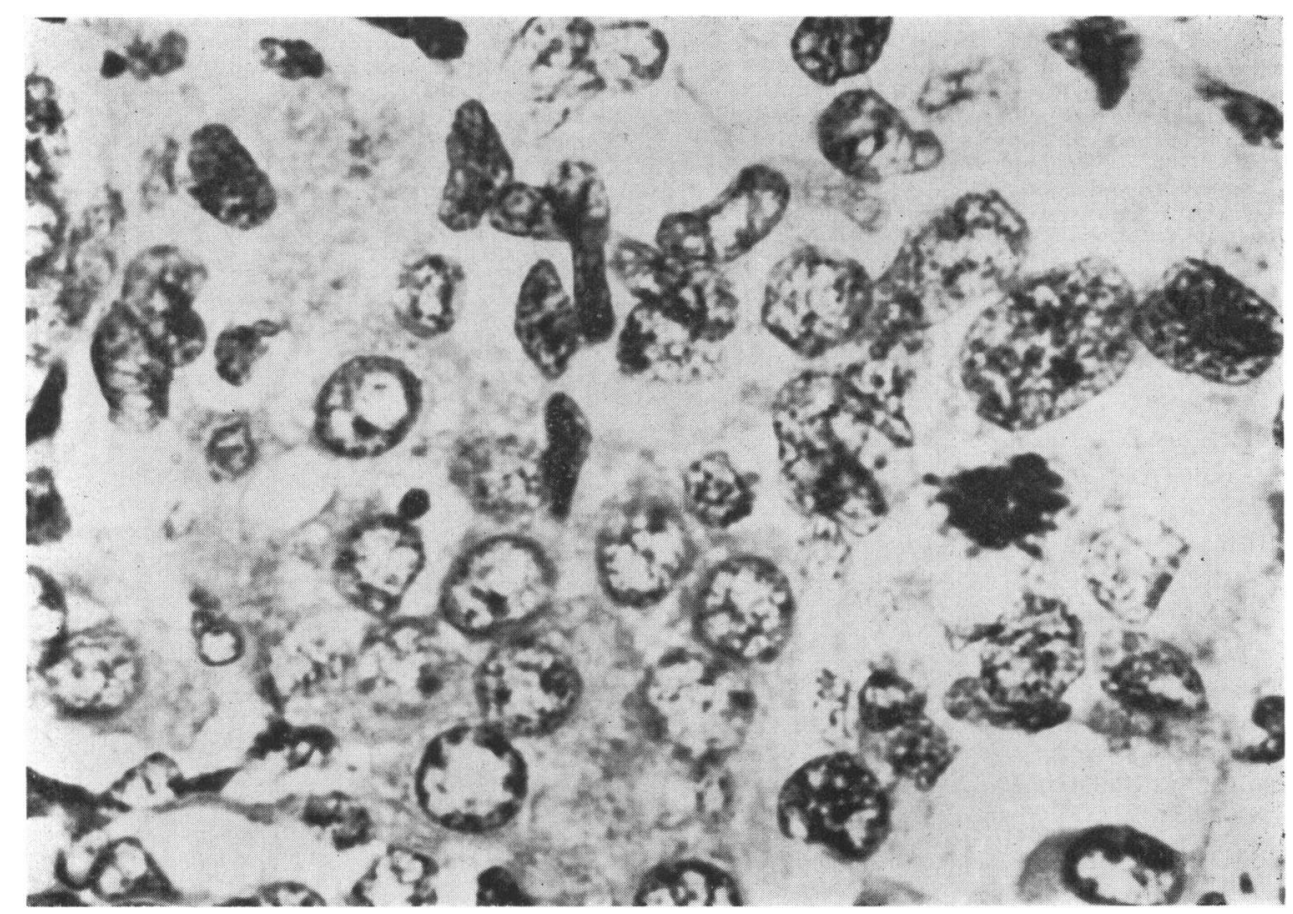

FIG. 4.-A view of interstitial cells in the testis of a dysmature male infant. Note the variation in nuclear size, the mitotic figure, and abundant pale cytoplasm of the cells. (H. and $E . \quad \times 1230$.)

homologous to theca luteinization is seen, though its recognition is less obvious. An illustration of such a change is seen in Fig. 4, taken from the testis of an infant of 36 weeks' gestation and birthweight $1450 \mathrm{~g}$ (birthweight score -2). The mitotic activity and the nuclear and cytoplasmic changes indicate a degree of reactivity very similar to that described in ovarian tissues in the present paper. While no studies have been carried out on the male 'equivalent' of ovarian cysts with theca luteinization, it is possible that a homologue may exist. The need for closer attention to endocrine function in dysmature newborns of both sexes appears to be obvious. It seems that the presence of follicular ovarian cysts in newborn females may prove to be a subtle indicator of hormonal imbalance in the fetoplacental unit, and for this reason alone deserves closer attention.

I am grateful to Dr. A. H. T. Robb-Smith, Director of the Gibson laboratories, Radcliffe Infirmary, Oxford, for permission to use Department records, to Mrs. Jan Slee for her help in tracing the cases, and to Professor $M$. Gent of the Department of Clinical Epidemiology and Biostatistics, McMaster University, Hamilton, Ontario, Canada, who carried out statistical analyses and gave advice.

\section{REFERENCES}

Aherne, W., and Dunnill, M. S. (1966). Quantitative aspects of placental structure. fournal of Pathology and Bacteriology, 91, 123.

Ahlvin, R. C., and Bauer, W. C. (1957). Luteinized cysts in ovaries of infants born of diabetic mothers. American fournal of Diseases of Children, 83, 107.

Blum, D., Dodion, J., Loeb, H., Wilkin, P., and Hubinont, P. O. (1969). Studies on hypoglycaemia in small-for-dates newborns. Archives of Disease in Childhood. 44, 304.

Butler, N. R., and Alberman, E. D. (1969). Perinatal Problems, Appendix table $4 \cdot 2 \mathrm{~b}$. Livingstone, Edinburgh and London.

Cathro, D. M., Forsyth, C. C., and Cameron, J. (1969). Adrenocortical response to stress in newborn infants. Archives of Disease in Childhood, 44, 88.

Connon, A. F. (1964). Immunological assay of human chorionic gonadotrophin in rhesus-sensitised women. Lancet, 1, 747.

Govan, A. D. T., and Mukherjee, C. L. (1950). Maternal toxaemia and foetal ovarian activity. Fournal of Obstetrics and Gynaecology of the British Empire, 57, 525.

Gruenwald, P. (1969). Growth and maturation of the foetus and its relationship to perinatal mortality. In Perinatal Problems, p. 141. Ed. by N. R. Butler and E. D. Alberman. Livingstone, Edinburgh and London.

Loraine, J. A., and Mathew, G. D. (1950). Chorionic gonadotrophin in toxaemias of pregnancy. Fournal of Obstetrics and Gynaecology of the British Empire, 57, 542.

Loraine, J. A., and Mathew, G. D. (1953). The placental concentration of chorionic gonadotrophin in normal and abnormal pregnancy. Fournal of Obstetrics and Gynaecology of the British Empire, 60, 640.

McCarthy, C., and Pennington, G. W. (1964). Maternal chorionic gonadotrophin concentration as an aid to the antenatal prediction of hemolytic disease of newborn infant. American fournal of Obstetrics and Gynecology, 89, 1069. 
Macdonald, R. R. (1972). Impairment of intrauterine growthearly warning by cervical mucus ferning. Fournal of Obstetrics and Gynaecology of the British Commonwealth, 79, 1087.

Macdonald, R. R., Goulden, R., and Oakey, R. E. (1972). Cervical mucus, vaginal cytology and steroid excretion in recurrent abortion. Obstetrics and Gynecology, 40, 394.

Morison, J. E. (1970). Foetal and Neonatal Pathology, 3rd ed., p. 204. Butterworths, London

Ober, W. B., and Bernstein, J. (1955). Observations on the endometrium and ovary in the newborn. Pediatrics, 16, 445.
Pryse-Davies, J., and Dewhurst, C. J. (1971). The development of $\frac{\rho}{\supset}$ the ovary and uterus in the foetus, newborn and infant: a morphological and enzyme histochemical study. fournal of Pathology, 103, 5.

Richardson, G. S. (1967). Ovarian Physiology. Churchill, London. Spivack, M. (1934). Polycystic ovaries in the newborn and early infancy and their relation to the structure of the endometrium. American fournal of Obstetrics and Gynecology, 27, 157.

Valdes-Dapena, M. A. (1967). The normal ovary of childhood. Annals of the New York Academy of Scierces, 142, 597. 